\title{
Effect of Bottom Ash and Fly Ash as a Susceptor Material on The Properties of Aluminium Based Composites Prepared by Microwave Sintering
}

\author{
Wan Nur Azrina Binti Wan Muhammad ${ }^{1}$, , Muhammad Firdaus Bin Idris ${ }^{1}$, Md. Nor Anuar Bin Mohamad ${ }^{2}$, Saliza Azlina \\ Binti Osman ${ }^{3}$ \\ ${ }^{1}$ Department of Material Engineering \& Design, Faculty of Mechanical Engineering \& Manufacturing, Universiti Tun Hussein \\ Onn Malaysia, Parit Raja, Johor, Malaysia \\ ${ }^{2}$ Department of Thermofluid Engineering, Faculty of Mechanical Engineering \& Manufacturing, Universiti Tun Hussein Onn \\ Malaysia, Parit Raja, Johor, Malaysia \\ ${ }^{3}$ Department of Manufacturing and Industrial Engineering, Faculty of Mechanical Engineering \& Manufacturing, Universiti Tun Hussein \\ Onn Malaysia, Parit Raja, Johor, Malaysia
}

\begin{abstract}
The use of aluminium as a single material in automotive applications is not suitable without a mixture with reinforcement materials that can support the properties at high temperature. In this study, aluminium based composite were prepared with weight percentage of $\mathrm{SiC}$ reinforcement, varying from 5 to $20 \mathrm{wt} \%$. Aluminium powder and reinforcement materials were mixed using ball milling machine with speed of $100 \mathrm{rpm}$ for 2 hours. The powder mixture were then compressed at pressure 4 tonnes with 5 minutes holding time. The compact samples were sintered using microwave sintering technique. Microwave sintering techniques in this study using two different types of susceptor materials that are bottom ash and fly ash. Sintered aluminium based composites using bottom ash susceptor material involving the sintering temperature of $526^{\circ} \mathrm{C}$ for 30 minutes whereas for the samples sintered using fly ash susceptor material, involving a temperature of 523 ${ }^{\circ} \mathrm{C}$ for 15 minutes. From the result, the sintered samples using fly ash susceptor material, showed higher density with a value of $2.1933 \mathrm{~g} / \mathrm{cm}^{3}$ compared to bottom ash $2.0002 \mathrm{~g} / \mathrm{cm}^{3}$ and having the higher hardness value $72.1315 \mathrm{HV}$ compared to bottom ash $50.0511 \mathrm{HV}$. The using of fly ash could affect the heating rate during the sintering process which could influence the properties of aluminium based composites. In conclusion, the type of susceptor could affect the physical and mechanical properties of aluminum-based composite reinforced with silicon carbide.
\end{abstract}

\section{Introduction}

Aluminium based composite is the material that is in category of metal matrix composites. The aluminium based composites material comprising aluminium as the matrix material and the reinforcing material that normally used silicon carbide $\mathrm{SiC}$ to change the properties of the original material to be stronger in terms of physical and mechanical properties. The automotive industry today has a lot of application which need the use of composite materials for replacing aluminium products such as vehicle components. Components such as disc brakes, pistons and engine block is a component that is usually manufactured using aluminium composites [1]. Silicon carbide ( $\mathrm{SiC})$ material, is a compound consisting of silicon and carbon. $\mathrm{SiC}$ is one of the types of reinforcement materials used in metal matrix composites. The purpose of $\mathrm{SiC}$ in the metal matrix composite as reinforcement to strengthen the existing microstructure and properties of the matrix material used. For example, the matrix material used in this study are aluminum. With the addition of reinforcement materials such as $\mathrm{SiC}$, physical and mechanical properties of the material will be changed. With the use of applications that are often associated with friction such as disc brakes, the addition of $\mathrm{SiC}$ in metal matrix composite material is very suitable because it will increase the wear resistance properties of the material [2]. Generally, Powder metallurgy (PM) process is well known to be one of excellent metal forming techniques for producing high quality structural components with near-net shape and also can produce alloys and composites that cannot be fabricated by conventional melting and casting processes [3].

Starting with the process of mixing metal powder in which the matrix material and reinforcement material to be mixed by using ball milling machine. This mixing process is intended to provide a homogeneous mixture of matrix material and reinforcing material. In the usual PM production sequence, the powders are compressed into the desirable shape and then heated to cause bonding of the particles into a hard, rigid mass [3]. The heating process namely as sintering. Sintering is a heat treatment operation performed on the compact to bond its metallic particles, thereby increasing strength and hardness [4]. There are challenging demands from the PM industry for new and improved sintering process with finer microstructures and enhanced physical and mechanical properties. And thus, this is where the microwave technology is found to be advantages compared to the conventional sintering technique [5]. Microwave sintering involves a microwave energy, form an electromagnetic energy at frequencies between $300 \mathrm{MHz}$ rates up to $300 \mathrm{GHz}$ [3]. In microwave heating, the material used for the sintering will work alongside the microwave absorbing electromagnetic energy which in turn is converted into heat. Theoretically, microwave heating is a method where heat is generated in the material first and then followed by heating the entire volume of material. In microwave sintering process, the susceptor material was turned the microwave energy into

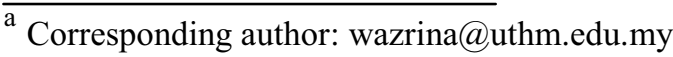


sensible infrared heat energy which was used to sinter the compacted sample. In addition, the susceptor material was helped in distributing microwave energy more evenly which reduced run away heating. According to previous studies by Oghbaei \& Mirzaee [5] involving austenitic stainless steel (316L) and ferritic (434L) which had been sintered by both technique of sintering, microwave and conventional sintering, respectively. In their study, it found that the microwave sintering technique indeed has a rapid heating time compared to conventional sintering techniques. The sintering technique used also plays a role in which the microstructure formed by sintering technique depends on whether the techniques used a conventional sintering or microwave sintering technique. The microstructure formed for both of these techniques showed a different where microstructure of the sample that has been sintered by conventional sintering techniques looked coarser than the samples sintered by microwave sintering technique. This is because the microwave sintering restrict the microstructural coarsening. Upadhyaya et al. [5] compared a difference on the heating mode on microstructure and mechanical properties of materials $92.5 \mathrm{~W}-6.4 \mathrm{Ni}-1.1 \mathrm{Fe}$ alloy. The rate of microwave heating is $20^{\circ} \mathrm{C} / \mathrm{min}$ while the conventional furnace is heating by $5^{\circ} \mathrm{C} / \mathrm{min}$. The results obtained also showed a different microstructure for both sintering techniques. The microstructure of the sample sintered by microwave sintering technique was finer than the microstructure sintered by conventional sintering techniques. Besides that, from analysis phase in conventional sintering techniques, it indicate that the presence of brittle intermetallic phase but it does not seen at the samples that has been sintered by the microwave sintering [5]. The advantages of microwave sintering can be proved by the properties of a sintered material. This is due to the sintering method will influence the size of the microstructure and the pore size. In conventional sintering, the microstructure is coarser and the pore size is bigger whereas microwave sintering techniques produce smaller pores and lead to more robust power generated. The study has been proved by Dinesh Agrawal [6], where the test has been conducted on a sample hollow cylinder FC-208 proven sample using conventional techniques fail to load $320 \mathrm{lbs}$ while the samples using microwave sintering technique failed at load $430 \mathrm{lbs}$. In this study, the advantages of the microwave sintering is used to prepared the aluminium based composites reinforced with silicon carbide by using two types of susceptor i.e. bottom ash and fly ash. The function of the susceptor in microwave sintering is important as it could heat quickly, retain and radiating the heat to the sample.

\section{Experimental Procedure}

In this study, the material that has been used was aluminium powder with various percentage of $\mathrm{SiC}$ from 5 $w t \%, 10 w t \%, 15 w t \%$ and $20 \mathrm{wt} \%$. Both powders were mixed in ball milling at 100rpm for 2 hours. The mixture of the powder were compacted at 4 tonnes load and sintered in microwave oven. The microwave oven was modified by inserting three insulator board and used two type of susceptor i.e fly ash and bottom ash. Figure 1 shows the schematic diagram of microwave oven modification set up. Before sintering the materials, the temperature calibration has been done to determine the sintering temperature and heating rates. The compacted samples had been sintered at $526^{\circ} \mathrm{C}$ in 30 minutes for bottom ash susceptor and $523^{\circ} \mathrm{C}$ in 15 minutes for fly ash susceptor. The susceptor is used to ensure that green powder samples are being exposed sufficiently to the electric field at high temperature even though the penetration of susceptor decreases as the temperature risen. A susceptor is a component that has high dielectric loss while passing through the low loss material with little drop in energy instead of only absorbing energy. At lower temperature, susceptor material absorbs microwave and reaches higher temperature and transfer the heat to the sample [5]. Both sintering processes did not have a holding time because the process was too fast compared to conventional sintering technique. The sintered samples were $15 \mathrm{~mm}$ in diameter with $8 \mathrm{~mm}$ in thickness. The bulk density and apparent porosity of the sintered samples were measured according to Archimedes principle by immersion test and electronic balancer with the accuracy of $+0.0001 \mathrm{~g}$. Microstructure observation was conducted by using optical microscopy. The hardness of the sintered samples was measured by means of Vickers Hardness Tester with an indenting load of $30 \mathrm{kgf}$ and a holding time of $10 \mathrm{~s}$.

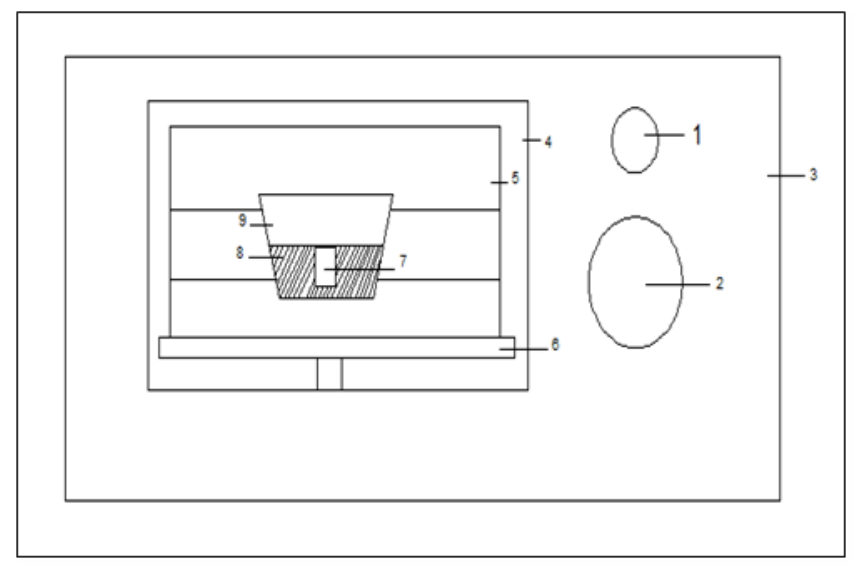

Figure 1. Temperature calibration profile of microwave sintering using bottom ash susceptor. 1) Temperature controller, (2) Time control button, (3) Microwave oven, (4) Controllled atmosphere chamber, (5) Insulator boards, (6) Turntable, (7) Sample, (8) susceptor, (9) crucible

\section{Results and Discussion}

\subsection{Heating rate}

Heating rate of the microwave sintering by using bottom ash and fly ash susceptors has been determined by performing the temperature calibration before conducting the sintering process. It is important to study the effect of 
type of susceptors to the heating rate during microwave sintering. During temperature calibration, temperature data has been taken in every 5 minutes as shown in Figure 2.

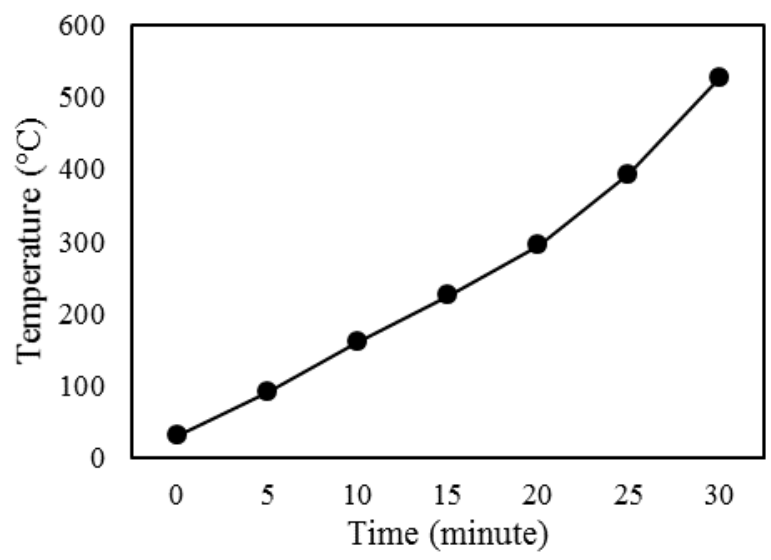

Figure 2. Temperature calibration profile of microwave sintering using bottom ash susceptor

In Figure 2, it shows the increase of temperature as time increased for microwave sintering using bottom ash as a susceptor material. It took 30 minutes to achieve the sintering temperature of $526^{\circ} \mathrm{C}$.

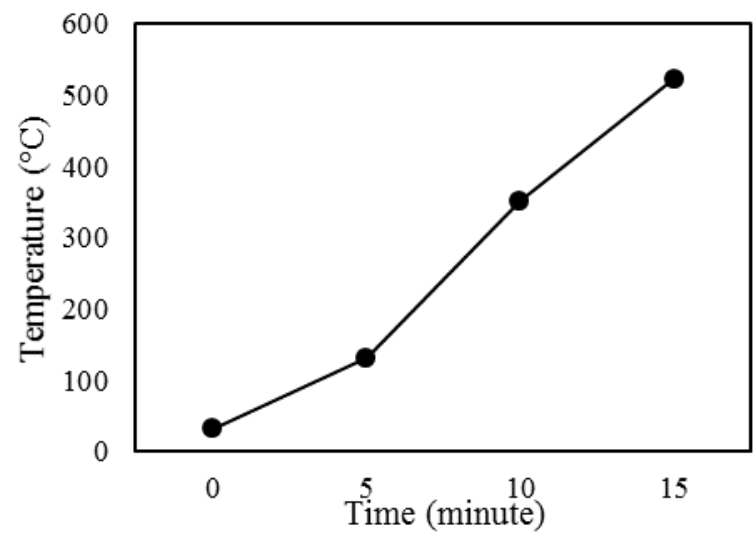

Figure 3. Temperature calibration profile of microwave sintering using fly ash susceptor

In Figure 3 shows the temperature calibration profile for sintering process using fly ash susceptor. It showed that the temperature increased up to $523^{\circ} \mathrm{C}$ only in 15 minutes. It means that the heating rate of the sintering process using fly ash susceptor is higher than bottom ash susceptor. The difference in heating rates has been attributed to the difference of composition of susceptor. Bottom ash and fly ash contain different percentage of silica. Fly ash has higher percentage of silica compared to bottom ash. The silica is an element that has high thermal conductivity. The higher heating rate has been attributed by the element silica in susceptor materials that has been used. Higher heating rate would improve the sintering process using microwave. This has allowed the microwaves to penetrate and then the susceptor will radiate the heat energy to the sample. The microwave simultaneously coupled with green body sample and penetrated heat internally due to penetrating feature of microwave in samples. This was led to volumetric heating of samples with short duration. [7]

\subsection{Microstructure observation}

Figure 4 and Figure 5 show the microstructure of aluminium based composites sintered by microwave sintering using bottom ash susceptor and fly ash susceptor, respectively. From the microstructure, white region refers to the aluminium matrix, grey region refers to $\mathrm{SiC}$ and black region refers to the presence of porosity. In the Figure 4, it was noted that the porosity of the sample sintered with bottom ash susceptor can be clearly seen compared to the samples that sintered with fly ash susceptor. In Figure 5, the microstructure is smooth and less pores. The presence of pores in the sample is related to microwave sintering technique which depend on the heating rate used in the microwave oven [7]. It is proved that the heating rate during microwave sintering is better when used fly ash as the susceptor.

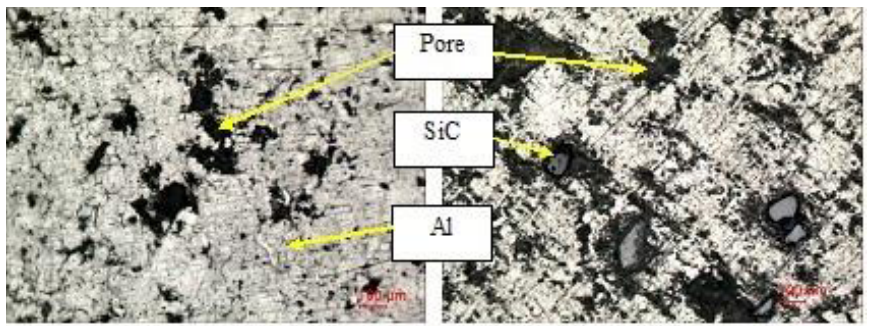

(a)

(b)

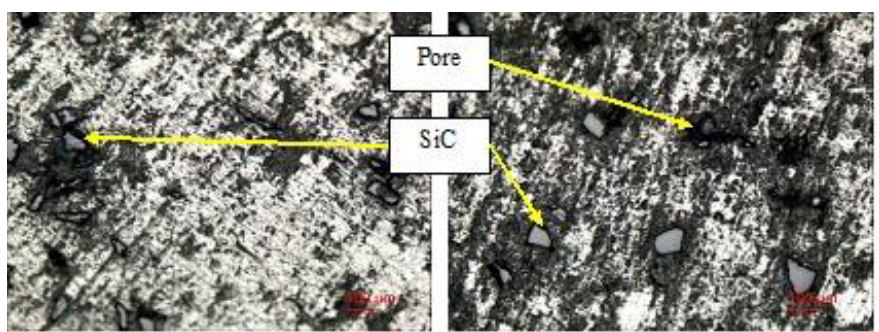

(c)

(d)

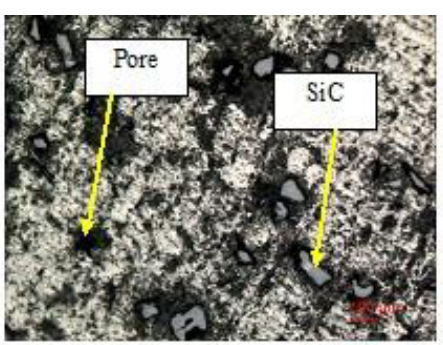

(e)

Figure 4: Microstructure behaviour at different composition by using bottom ash susceptor: (a) $0 \mathrm{wt} \%$, (b) $5 \mathrm{wt} \%$, (c) 10 wt $\%$, (d) $15 \mathrm{wt} \%$, (e) $20 \mathrm{wt} \%$ 


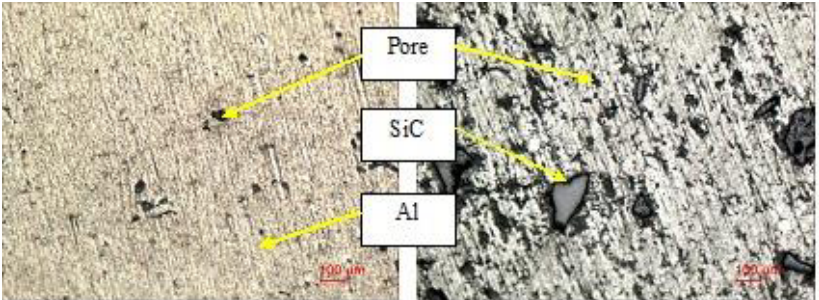

(a)

(b)

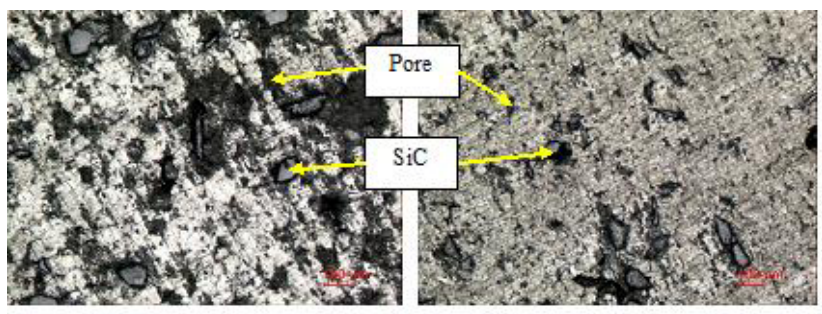

(c)

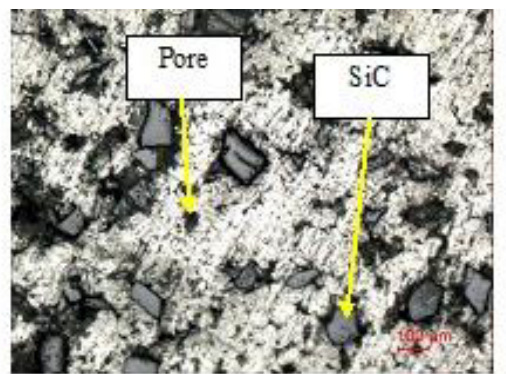

(e)

Figure 5. Microstructure of aluminium composites reinforced with $\mathrm{SiC}$ at different composition by using fly ash susceptor: (a) $0 \mathrm{wt} \%$, (b) $5 \mathrm{wt} \%$, (c) $10 \mathrm{wt} \%$, (d) $15 \mathrm{wt} \%$, (e) $20 \mathrm{wt} \%$.

\subsection{Density}

In Figure 6 it shows the density of the aluminium based composites as function of percentage of $\mathrm{SiC}$ reinforcement. As it can be seen, the density of the sample for both type susceptor shows not much different but it shows the increment as $\mathrm{SiC}$ reinforcement increased. However, In previous studies, the density increased as the content of $\mathrm{SiC}$ reinforcement increased [9]. This is due to percentage of $\mathrm{SiC}$ reinforcement reduce the pores in aluminum matrix. Besides that, the increment of density showed the good densification in the sample by using microwave sintering and this could be related to the function of susceptor that controlled the heating rates during the sintering process. Rapid heating during microwave sintering generally improved the densification for certain sintered. The rapid heating allows atomic diffusion for sintering process. As a result, more atoms move to points of contact between powder particles to form sintering necks. When the necks grow, the pore sizes are reduced this causes an increase in the final density of the sintered products.

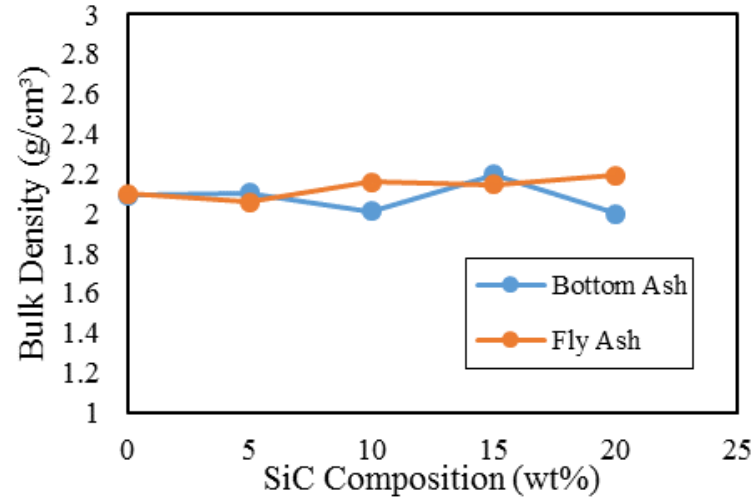

Figure 6. Bulk density of aluminium composites as function of $\mathrm{SiC}$ composition.

\subsection{Porosity}

Porosity test is a physical test to determine the percentage of porosity exist in the sample. Existing porosity of the material will affect the density of the sample. From Figure 7 it shows that aluminum composite samples sintered with fly ash has lower percentage of porosity compared to the aluminum composite material that sintered using bottom ash susceptor material. The value of apparent porosity is related to the value of bulk density. The presence of porosity reduced the densification in sintered aluminum composites. Microwave heating rate also plays a role which the high heating rates will contribute to a low porosity [8].

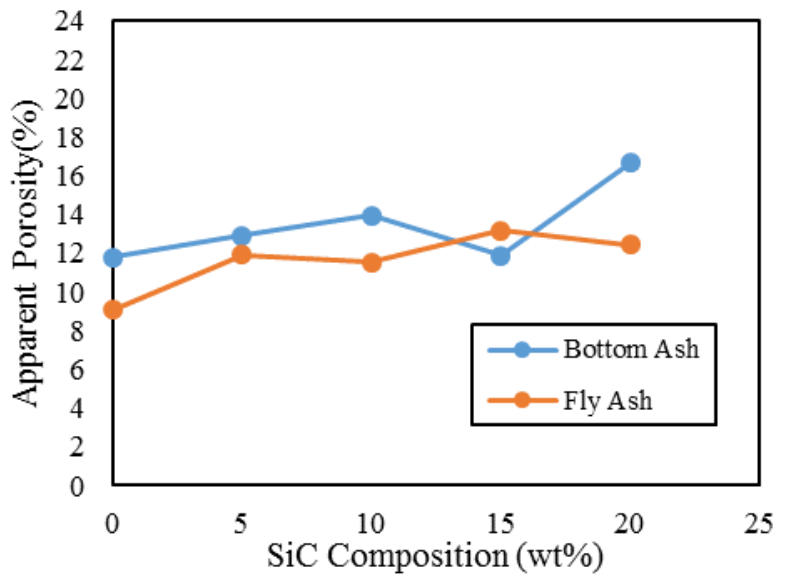

Figure 7. Porosity of aluminium composites as function of $\mathrm{SiC}$ composition.

\subsection{Hardness}

Figure 8 shows the relationship between hardness and $\mathrm{SiC}$ composition for aluminium based composites prepared by microwave sintering with two different susceptor used. The value of hardness was increased with increasing $\mathrm{SiC}$ composition for both type of susceptor. By using fly ash as susceptor, the value of hardness is higher than that of sintered by using bottom ash as susceptor material. It revealed that the use of fly ash 
could improve the properties of aluminium composites. The improvement of the hardness is related to the densification of the composites. High density and low porosity will give higher hardness value. In microwave sintering, the densification of the sample is related to the susceptor material that used during the process. The properties of susceptor material could affect the heating rate during sintering. Fly ash and bottom ash contain the silicon dioxide (silica) in its composition. The element of silicon dioxide in fly ash is higher (65.01 wt \%) than bottom ash (51.18 wt \%) [10]. Silicon dioxide has high thermal conductivity. Higher thermal conductivity contribute to the effectiveness of sintering process as the wave could be absorb more and transfer the heat in the sample [3]. As a consequence, the heating rate is increased and sintering of the composite samples were completed. The completion of sintering process could be measure by the improvement of the physical and mechanical properties of the composites.

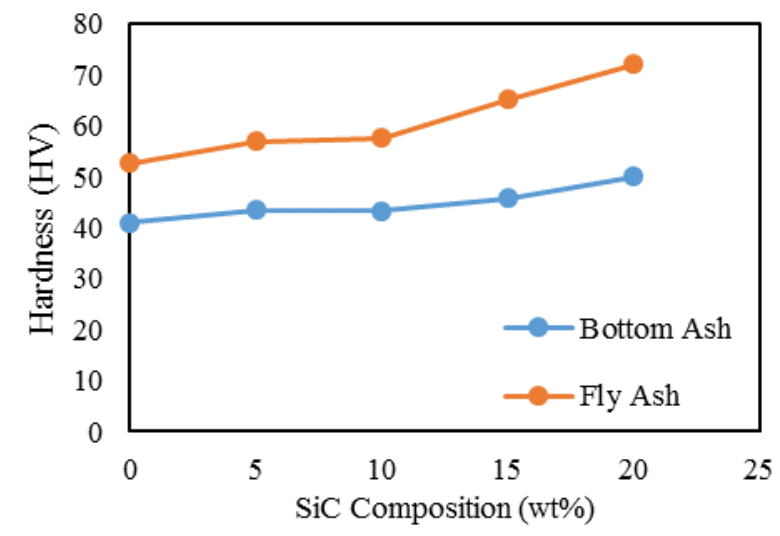

Figure 8. Hardness of aluminium composites as function of $\mathrm{SiC}$ composition.

\section{Conclusion}

The main objectives of the study are to determine the effect of bottom ash and fly ash as susceptor during microwave sintering which could improve the physical and mechanical properties of sintered aluminium composites reinforced with silicon carbide. It was found that fly ash susceptor would increase the heating rates during microwave sintering of aluminum based composites samples. Fly ash susceptor has been achieved the higher density, lower porosity and highest hardness compared to the sample prepared by using bottom ash susceptor. The good quality of the sintered sample due to the composition of silica in fly ash is higher than bottom ash. The silica in susceptor material helps to improve the heating rates during sintering due to high thermal conductivity properties of silica. Overall, it has been concluded that sintered aluminium based composite reinforced with silicon carbide with fly ash susceptor during microwave sintering improved the mechanical and physical properties of the composites.

\section{Acknowledgement}

The work was partly supported by University Tun Hussein Onn Malaysia under the Research Supporting Grant Scheme (RSGS) Vote U104.

\section{References}

[1] M. Walczak, D. Pieniak, and M. Zwierzchowski, "The tribological characteristics of $\mathrm{SiC}$ particle reinforced aluminium composites," Arch. Civ. Mech. Eng., vol. 15, no. 1, pp. 116-123, 2014.

[2] K. R. Padmavathi and R. Ramakrishnan, "Tribological behaviour of Aluminium Hybrid Metal Matrix Composite," Procedia Eng., vol. 97, pp. 660-667, 2014.

[3] P.Perez, G.Garces., P.Adeva, Influence of texture on the mechanical properties of commercially pure magnesium prepared by powder metallurgy. Journal Material Science, 2007. 42: p. 39693976.

[4] Groover M.P (2002). "Fundamental of Modern Manufacturing."2nd .ed. John Wiley \& Sons,Inc. 187.

[5] Oghbaei, M., and O. Mirzaee. "Microwave versus conventional sintering: A revies of fundamentals, advantages and applications. " Alloys and Compounds, pp 175-189, 2010

Dinesh Agrawal (The Pennsylvania State University), "Microwave Sintering of Ceramics, Composites and Metallic Materials, and Melting of Glasses," Transactions of the Indian Ceramic Society, vol. 65, no. 3. pp. 129-144, 2006.

[7] S. Leparoux. S. Vaucher, O. Beffort, Assessment of Microwave Heating for Sintering of $\mathrm{Al} / \mathrm{SiC}$ and for in-situ Synthesis of TiC, Adv. Eng Mater 5, pp 449-453, 2003

[8] O. Ertugrul, H.-S. Park, K. Onel, and M. WillertPorada, "Effect of particle size and heating rate in microwave sintering of $316 \mathrm{~L}$ stainless steel," Powder Technol., vol. 253, pp. 703-709, 2014.

[9] M. V. Krishna and A. M. Xavior, "An Investigation on the Mechanical Properties of Hybrid Metal Matrix Composites," Procedia Eng., vol. 97, pp. 918-924, 2014.

[10] Y. Zarina, A.M.Mustafa Al Bakri, H. Kamarudin, I.K.Nizar and R. Rafiza, " Review on the various ash from palm oil waste as geopolymer material." Rev. Adv. Mater. Sci., vol. 34. no.1, pp. 37-43, 2013. 